\title{
GHR gene transcript heterogeneity may explain phenotypic variability in GHR pseudoexon (64) patients
}

\author{
Sumana Chatterjee1, Emily Cottrell ${ }^{1}$, Stephen J Rose ${ }^{2}$, Talat Mushtaq $^{3}$, Avinaash V Maharaj ${ }^{1}$, Jack Williams ${ }^{1}$, \\ Martin O Savage ${ }^{1}$, Louise A Metherell ${ }^{1}$ and Helen L Storr ${ }^{1}$ \\ ${ }^{1}$ Centre for Endocrinology, William Harvey Research Institute, Barts and the London School of Medicine \& Dentistry, Queen Mary University of London, \\ London, UK \\ ${ }^{2}$ Birmingham Heartlands Hospital, University Hospitals Birmingham NHS Foundation Trust, Birmingham, UK \\ ${ }^{3}$ The Leeds Teaching Hospital NHS Trust, Leeds, UK
}

Correspondence should be addressed to H L Storr: h.I.storr@qmul.ac.uk

\begin{abstract}

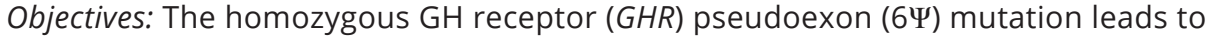
growth hormone insensitivity (GHI) with clinical and biochemical heterogeneity. We investigated whether transcript heterogeneity (6Y-GHR to WT-GHR transcript ratio) and/or concurrent defects in other short stature (SS) genes contribute to this. Methods: $6 \Psi-G H R$ and WT-GHR mRNA transcripts of four $6 \Psi$ patients (height SDS -4.2 to -3.1 ) and one control fibroblast were investigated by RT-PCR. Transcripts were quantified by qRT-PCR and delta delta CT analysis and compared using ANOVA with Bonferroni correction. In eleven $6 \Psi$ patients, 40 genes known to cause GHI/SS were analysed by targeted next generation sequencing.

Results: RT-PCR confirmed $6 \Psi-G H R$ transcript in the $6 \Psi$ patients but not in the control. $6 \Psi-G H R$ transcript levels were comparable in patients 1 and 3 but significantly different among all other patients. The mean $6 \Psi: W T$ transcript ratios ranged from 29-71:1 for patients $1-4$ and correlated negatively with height SDS $(R=-0.85 ; P<0.001)$. Eight deleterious variants in six genes were detected, but the number of gene hits did not correlate with the degree of SS in individual $6 \Psi$ patients.

Conclusion: Variable amounts of $6 \Psi$ - and WT-GHR transcripts were identified in $6 \Psi$ patients but no $6 \Psi$ transcript was present in the control. Higher $6 \Psi:$ WT-GHR transcript ratio correlated with SS severity and may explain the phenotypic variability. Analysis of known SS genes suggested that phenotypic variation is independent of the genetic background. This is the first report of transcript heterogeneity producing a spectrum of clinical phenotypes in different individuals harbouring an identical homozygous genetic mutation.
\end{abstract}

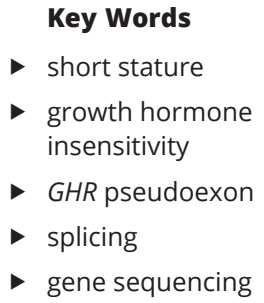

Endocrine Connections (2020) 9, 211-222

\section{Introduction}

Growth hormone insensitivity (GHI) is characterised by growth failure, IGF1 deficiency and normal or elevated GH levels. GHI encompasses a spectrum of genetic, phenotypic and biochemical abnormalities associated with growth failure $(1,2)$. Monogenic defects of the GH-IGF1 axis leading to GHI have been identified in the
GHR (3), STAT5B (4), IGFALS (5), PAPPA2 (6) and IGF1 (7) genes.

Splicing is the process by which introns are precisely identified and excised with the remaining exons united to form a translatable message (8). Intronic DNA frequently encodes potential exonic sequences (9). https://ec.bioscientifica.com

https://doi.org/10.1530/EC-20-0026

C 2020 The authors Published by Bioscientifica Ltd

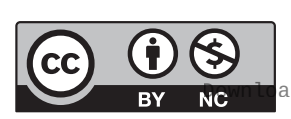

This work is licensed under a Creative Commons Attribution-NonCommercial 4.0 International License. ded from Bioscientifica.com at 04/26/2023 10:24:57AM 
These 'pseudoexons' are sequences between 50 and 300 nucleotides in length with apparently viable $5^{\prime}$ and $3^{\prime}$ splice sites $(10,11)$. Under normal circumstances, they are actively suppressed and not recognised by the splicing machinery $(10,12,13,14,15)$. However, point mutations in intronic DNA sequences can lead to the creation of new donor $\left(5^{\prime}\right)$, acceptor $\left(3^{\prime}\right)$ splice or branch sites and activation of 'pseudoexons'. This often occurs within 100 nucleotide bases of the canonical splice site resulting in the inclusion of intronic sequences immediately flanking the exonic sequence (16). Inclusion of intronic sequences by aberrant splicing is a recognised rare cause of several genetic diseases including neurofibromatosis type 1, cystic fibrosis, Duchenne and Becker muscular dystrophies $(8,17)$.

The intronic growth hormone receptor (GHR) pseudoexon $(6 \Psi)$ mutation was first reported in 2001 in two sets of siblings from a highly consanguineous Pakistani family with growth failure and features of relatively mild GHI (18). In 2007, an additional seven $6 \Psi$ patients were reported with a wider range of short stature (SS) phenotypes (19). In 2013, Walenkamp et al. described two further $6 \Psi$ patients with growth failure followed by partial catch-up growth without treatment (20). We recently reported the spectrum of clinical and biochemical features in $206 \Psi$ subjects, which included eleven previously reported individuals and nine additional patients (21).

The GHR $6 \Psi$ mutation (c. $618+792 \mathrm{~A}>\mathrm{G})$ is a homozygous point mutation in the final nucleotide of the pseudoexon, altering the $5^{\prime}$ pseudoexon splice site in intron 6 of the GHR gene. This results in activation of the pseudoexon sequence, efficient splicing and inclusion of an additional 108 bases between exons 6 and 7. This results in the inclusion of 36 amino acids in the extracellular domain of the GHR protein (18), and functional work demonstrated that the mutant GHR protein impaired trafficking rather than signalling (22).

Under normal circumstances, the GHR pseudoexon is disregarded, that is, not spliced into the mature GHR mRNA. Previous work confirmed that binding of heterogenous nuclear ribonucleoprotein E1 (hnRNP E1) and U1 small nuclear ribonucleoprotein (snRNP) to the pre-spliceosomal complex prevented $6 \Psi$ inclusion (8).

GHR $6 \Psi$ mutation patients exhibit a wide spectrum of clinical and biochemical variability, even between individuals within the same kindred (21). The height SDS of 20 GHR $6 \Psi$ patients previously described (21) varied between -1.7 and -5.9 with IGF1 SDS between -1.0 and -6.8 . Additionally, $50 \%$ patients had 'classical' GHI facial features and the remainder had completely normal facial appearance (21).

Splice mutations may not always be $100 \%$ efficient in causing aberrant splicing, and normal (WT) and mutant transcripts may exist concurrently due to competitive use of normal and mutant splice sites. Previous data suggested that, alongside the abnormally spliced GHR transcript, a small amount of normally spliced WT GHR mRNA was present in GHR $6 \Psi$ patients (18).

Analysis of cDNA of patients carrying different splice mutations of the same gene have shown that multiple abnormal splicing events occur alongside the production of the normal splice product, leading to a spectrum of phenotypes $(23,24,25)$. However, transcript variability has not previously been investigated in individuals with identical splice mutations.

The range of phenotypes observed in patients with the GHR $6 \Psi$ mutation may be related to the presence of transcript heterogeneity, that is, the ratio of abnormal (mutant) to normal (WT) GHR transcript. Genetic and environmental factors may also play a role in defining this ratio (19). We investigated for the first time, whether GHR gene transcript heterogeneity and/or concurrent defects in other known short stature genes contributed to the observed clinical variability of $6 \Psi$ subjects.

\section{Subjects and methods}

\section{Subjects}

The subjects were diagnosed with homozygous intronic

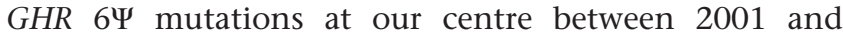
$2014(18,19,21)$. The referring physicians completed a proforma detailing the clinical and biochemical details at the time of DNA sampling for genetic analysis (21) and was prior to starting any growth promoting therapy. Height measurements were obtained using a wall-mounted stadiometer. Height was expressed as SDS according to the appropriate UK-WHO growth national standards $(26,27)$. IGF1 values were expressed as SDS based on the age and sex appropriate ranges provided by the host institution.

\section{Fibroblast culture}

Dermal fibroblasts from four GHR $6 \Psi$ subjects (patients 1-4) from two consanguineous Pakistani families were obtained by punch skin biopsies, which were performed according to established protocols $(28,29)$ after written informed consent was obtained. Control human fibroblasts (normal neonatal male dermal fibroblast cell line) were obtained

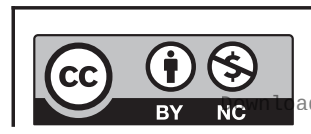

This work is licensed under a Creative Commons Attribution-NonCommercial 4.0 International License. ded from Bioscientifica.com at 04/26/2023 10:24:57AM 
from American Type Culture Collection (ATCC). Fibroblast cells were cultured in $75 \mathrm{~cm}^{2}$ cell culture flasks (Greiner BioOne, Germany) in High Glucose-DMEM (Sigma-Aldrich) supplemented with $20 \%$ foetal bovine serum (Invitrogen), 50 units/mL penicillin and $50 \mu \mathrm{g} / \mathrm{mL}$ streptomycin.

\section{Reverse-transcriptase PCR (RT-PCR)}

RNA was extracted from fibroblast cell lines using the RNAEasy kit (Qiagen) as per the manufacturer's instructions. One microgram RNA was reverse transcribed using the Moloney Murine Leukemia Virus Reverse Transcriptase (M-MLV RT) mix (Thermo Fisher Scientific) according to manufacturer's protocol. cDNA products from four patients and one control subject were amplified using the following intron skipping primers (Fig. 1A):

1. Primers directed to exon 5 of the GHR gene (forward; AGTGCAACCAGATCCACC) and the junction of exons 6 and 7 (reverse; GGAAAATGATGGACCCTATA) to amplify the wild-type (WT-GHR) transcript (Reaction 1).

2. Primers directed to the GHR $6 \Psi$ (forward; GGCACAGATCACTCCCAG) and the junction of exons 7 and 8 (reverse; GATTTCTACTTTCCATGGCTC) to

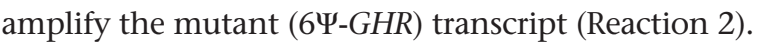

A
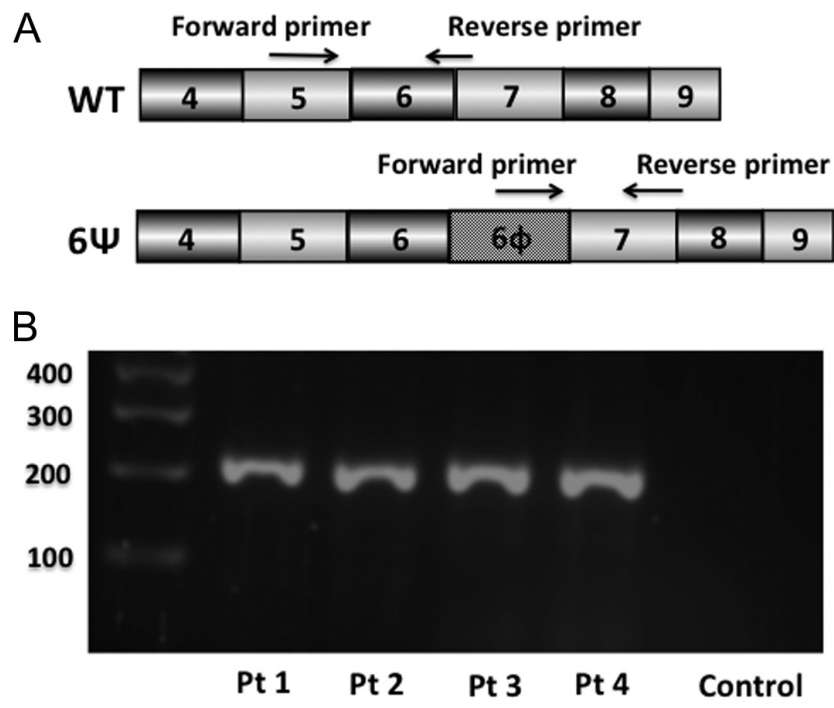

Figure 1

Reverse transcriptase PCR (RT-PCR) of WT and mutant transcripts in the $6 \Psi$ and control subjects. (A) Schematic diagram of the GHR gene showing the position of the $6 \Psi$ pseudoexon and intron skipping primers. $6 \Psi$, mutant pseudoexon transcript; WT, wild type GHR transcript. (B) $2 \%$ agarose gel showing products of RT-PCR Reaction 2: $6 \Psi$ transcript (228 bp) in all four $6 \Psi$ patients (patients 1-4) but not in the control subject. Bp, base pairs.
Thermocycling conditions were: heated lid $110^{\circ} \mathrm{C} ; 30$ cycles at $95^{\circ} \mathrm{C}$ for $30 \mathrm{~s}, 65^{\circ} \mathrm{C}$ to $55^{\circ} \mathrm{C}$ for $30 \mathrm{~s}$ and $72^{\circ} \mathrm{C}$ for $30 \mathrm{~s}$ followed by 10 cycles at $95^{\circ} \mathrm{C}$ for $30 \mathrm{~s}, 60^{\circ} \mathrm{C}$ for $30 \mathrm{~s}$ and $72^{\circ} \mathrm{C}$ for $30 \mathrm{~s}$. Products were visualised on a $2 \%$ agarose gel and verified by Sanger sequencing (GATC Biotech; https://www.gatc-biotech.com).

\section{Quantitative RT-PCR (qRT-PCR)}

The relative levels of WT-GHR and $6 \Psi-G H R$ mRNA transcripts were quantified by quantitative RT-PCR using the primer sets previously mentioned (Reactions 1 and 2). Expression levels of the two transcripts were determined quantitatively by the MX3000 real-time PCR system (Stratagene) using SYBR green (Kapabiosystems, USA). Ten nanograms of cDNA were added per $10 \mu \mathrm{L}$ reaction. Thermocycling conditions were: 1 cycle at $95^{\circ} \mathrm{C}$ for $3 \mathrm{~min}, 40$ cycles at $95^{\circ} \mathrm{C}$ for $3 \mathrm{~s}, 60^{\circ} \mathrm{C}$ for $20 \mathrm{~s}$ and $72^{\circ} \mathrm{C}$ for $10 \mathrm{~s}$ and 1 cycle at $95^{\circ} \mathrm{C}$ for $1 \mathrm{~min}, 60^{\circ} \mathrm{C}$ for $30 \mathrm{~s}$ and $72^{\circ} \mathrm{C}$ for $30 \mathrm{~s}$.

The relative expression levels of the two transcripts were compared in the four patients and one control. Gapdh was used as the internal reference gene, and five technical repeats for each patient were performed. For each experiment, five independent RNA extractions were assayed with three technical replicates. Relative mRNA expression (stated as mean \pm s.D.) was calculated by delta delta CT analysis $(\Delta \Delta \mathrm{CT})$, and values in patients and control were compared using one-way ANOVA with Bonferroni correction. $P$ value of $<0.05$ was taken as statistical significance.

\section{Genetic analysis by targeted gene sequencing}

Genomic DNA was isolated from peripheral blood leukocytes (Qiagen DNeasy Kit) from $116 \Psi$ subjects, including patients 1, 2 and 4 from whom skin fibroblasts were obtained. No DNA was available for patient 3 . Targeted sequencing of the coding, promotor and intronic regions (2000 bp upstream and 500 bp downstream of each target gene) of 40 short stature genes was undertaken (Table 1). This was processed on an Illumina HiSeq 2500 sequencing platform with paired end of 100 and a designated average coverage of 100× (Otogenetics, Norcross, GA, USA). The raw data from Otogenetics were analysed using DNA Nexus (DNAnexus Inc., Mountain View, CA, USA) by aligning to the $H$. sapiens GRCh37-b37 (1000 genomes Phase 1) reference genome with BWA-MEM FastQ Readmapper. VCF files were 
Table 1 Short stature genes included in the genetic analysis of $116 \Psi$ subjects.

\begin{tabular}{llll}
\hline GHR & IGFBP1 & SOS2 & MAP2K1 (MEK1) \\
IGFALS & IGFBP2 & RAF1 & MAP2K2 (MEK2) \\
STAT5B & IGFBP4 & BRAF & A2ML1 \\
IGF1 & IGFBP5 & NRAS & LZTR1 \\
PAPPA-2 & IGF2 & KRAS & SHOC2 \\
IGF1R & OBSL1 & HRAS & ARAF \\
IGFBP3 & CCDC8 & RRAS & NF1 \\
PAPPA & CUL7 & CBL & NPR2 \\
STAT3 & PTPN11 & RIT1 & ACAN \\
JAK2 & SOS1 & RASA2 & SHOX \\
\hline
\end{tabular}

Genetic analysis included review of known (GHR, IGFALS, STAT5B, IGF1, PAPPA2 and IGF1R) and putative (IGFBP3, PAPPA, STAT3, JAK2, IGFBP1, IGFBP2, IGFB4 and IGFBP5) monogenic defects of the GH-IGF1 axis leading to GHI and IGF1 resistance phenotypes. We also sought variants in genes associated with overlapping short stature syndromes $(2,34,35,36,37)$ 3M (OBSL1, CCDC8 and CUL7), Silver-Russell (IGF2) and Noonan (PTPN11, SOS1, SOS2, RAF1, BRAF, NRAS, KRAS, HRAS, RRAS, CBL, RIT1, RASA2, MAP2K1, MAP2K2, A2ML1, LZTR1, SHOC2, ARAF and NF2) syndromes. Other genes associated with short stature (ACAN (61, 62), NPR2 (63) and SHOX (64)) were also included in the analysis.

generated by Vendor Human Exome GATK-Lite Variant Caller (Unified Genotyper).

The resulting VCF files were uploaded to Ingenuity Variant Analysis (Qiagen) and results were analysed with the following filters: call quality $\geq 20$, read depth $\geq 10$ and data outside $5 \%$ of most exonically variable 100 base windows in healthy public genomes. Common variants were filtered out by excluding those with a minor allele frequency of $\geq 0.5 \%$ in the 1000 genomes, ExAC and the NHLBI exomes.

Genetic variants were investigated in silico by SIFT (score 0, predicted deleterious to 1 , predicted benign), PolyPhen-2 (score 0, predicted benign to 1, predicted deleterious) and CADD (Combined Annotation Dependent Depletion) score to predict the functional outcome. The CADD score assesses the negative effect of single nucleotide variants as well as insertion/deletions variants. A scaled CADD score of 20 represents a variant that is among the top $1 \%$ deleterious variants, and a scaled CADD score of 30 means that the variant is in the top $0.1 \%$.

\section{Ethical approval}

The study was approved by the Health Research Authority, East of England - Cambridge East Research Ethics Committee (REC reference: 17/EE/0178). Informed written consent for genetic research, skin biopsy and publication of clinical details was obtained from parents/ carers and the patients where appropriate.

\section{Results}

\section{Clinical phenotypes}

The subjects studied had a range of clinical and biochemical heterogeneity as previously described. Patients 1 (height SDS -3.6 and IGF1 SDS -2.0) and 4 (height SDS -3.1 and IGF1 SDS -2.5) were first cousins from a consanguineous Pakistani family with no dysmorphic facial features. Patients 2 (height SDS -4.2 and IGF1 SDS -2.5) and 3 (height SDS -3.8 and IGF1 SDS -2.3 ) are siblings from another consanguineous Pakistani family. Both had typical facial features of GHI with mid-facial hypoplasia, depressed nasal bridge and prominent forehead. The mean age at presentation of the four patients was 3.2 years (range $2.6-3.8$ years) (Table 2 ).

The mean age at presentation of the $116 \Psi$ patients who underwent targeted gene sequencing was 4.8 years (range 1.2 to 9.9 years), mean height SDS -4.1 (range -3.0 to -5.1 SDS) and mean IGF1 SDS was -2.6 (range -4.0 to -2.0 ). 10/11 patients and $1 / 11$ patients were from consanguineous Pakistani families and a nonconsanguineous Indian family, respectively. Consistent with our previous report (21), 6/12 (50\%) had facial features of GHI, as previously mentioned.

\section{WT and mutant GHR transcript expression}

In order to amplify the WT-GHR transcript, a RT-PCR reaction was performed (Reaction 1), using primers directed to exon 5 and the junction of exons 6 and 7 of the GHR gene (Fig. 1A). The WT-GHR transcript (193 bp) was identified in all four $6 \Psi$ subjects and the control. The $6 \Psi-G H R$ transcript was amplified by a RT-PCR reaction (Reaction 2) using primers directed to the GHR $6 \Psi$ and the junction of exons 7 and 8 of the GHR gene (Fig. 1A). The mutant $6 \Psi-G H R$ transcript (228 bp) was identified in all $6 \Psi$ subjects but not the control (Fig. 1B). Sanger sequencing verified all the predicted cDNA sequences.

\section{Quantification of the WT and mutant GHR transcripts}

qRT-PCR quantified the relative levels of the WT-GHR and mutant $6 \Psi-G H R$ transcripts, using the primer sets previously mentioned (Reactions 1 and 2).

WT-GHR mRNA expression (mean \pm s.D.) relative to control was $0.055 \pm 0.021,0.022 \pm 0.014,0.055 \pm 0.018$ and $0.049 \pm 0.034$ for patients $1-4$, respectively (Fig. 2A). This was significantly lower in all patients compared to control

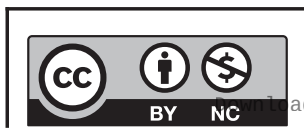

This work is licensed under a Creative Commons Attribution-NonCommercial 4.0 International License. ded from Bioscientifica.com at 04/26/2023 10:24:57AM 
Table 2 Phenotypic features and $6 \Psi-G H R$ to WT-GHR transcript ratios in the four $6 \Psi$ subjects.

\begin{tabular}{llcc}
\hline Patient & & Sex & Age (years) \\
\cline { 1 - 1 } 2 & $\mathrm{M}$ & 3.8 \\
3 & $\mathrm{~F}$ & 3.7 \\
4 & $\mathrm{M}$ & 2.6 \\
& $\mathrm{M}$ & 2.8 \\
\hline
\end{tabular}

\begin{tabular}{c}
\hline Height SDS \\
\hline-3.6 \\
-4.2 \\
-3.8 \\
-3.1 \\
\hline
\end{tabular}

\begin{tabular}{c}
\hline IGF1 SDS \\
\hline-2.0 \\
-2.5 \\
-2.3 \\
-2.5 \\
\hline
\end{tabular}

\begin{tabular}{c}
\hline Facial features \\
\hline $\mathrm{N}$ \\
$\mathrm{Y}$ \\
$\mathrm{Y}$ \\
$\mathrm{N}$
\end{tabular}

Mean 6 $\Psi / W T$ transcript ratio

39.2:1

$70.7: 1$

46.9:1

$6 \Psi$, mutant pseudoexon transcript; F, female; Facial features, facial features of classical GHI (frontal bossing, mid-facial hypoplasia); M, male; N, no; WT, wild type GHR transcript; $Y$, yes.

(1.001 \pm 0.016$)$; all $P$ values $<0.001$. This suggests that only small amounts of WT-GHR transcript are present in the GHR $6 \Psi$ patients.

Mutant $6 \Psi-G H R$ mRNA expression was calculated relative to patient 1 , rather than control, as mutant transcript expression was negligible in the control compared to the $6 \Psi$ subjects. Mutant $6 \Psi-G H R$ mRNA expression (mean \pm s.D.) relative to patient $1(1.003 \pm 0.004)$ were $0.552 \pm 0.061,1.003 \pm 0.180$ and $0.40 \pm 0.069$ for patients $2-4$, respectively, and $0.001 \pm 0.0003$ for control. There was no significant difference in $6 \Psi-G H R$ transcript

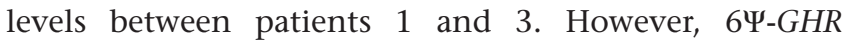
transcript levels were significantly different between all the other patients ( 1 and 2, 1 and 4, 2 and 3 and 3 and 4; $P<0.001$ and patients 2 and $4 ; P=0.017$ ) (Fig. 2B). This confirms variable amounts of mutant $6 \Psi-G H R$ transcript in the GHR $6 \Psi$ subjects, with negligible levels in control.

The mean 6\%:WT transcript ratios for patients 1-4 were 39:1, 71:1, 47:1 and 29:1, respectively (Table 2). These values correlated negatively with height SDS $(\mathrm{R}=-0.85, P$ value $<0.001)$ (Fig. 2C). This would suggest that shorter patients have transcript ratios in favour of the mutant GHR.

\section{Genetic analysis}

We analysed $116 \Psi$ subjects (which included patients 1 , 2 and 4) for genetic variants in 40 known human short stature genes. This revealed eight predicted deleterious variants in six genes (IGFALS, OBSL1, CBL, IGF1R, ACAN and CUL7) in eight of the $116 \Psi$ subjects (Table 3 ). Patients 9 and 10 had compound heterozygous missense variants in CUL7 and IGFALS, respectively (Table 3). The remaining $6 / 8$ variants were monoallelic (patients 2 , 4 , and 5-8). 4/6 variants were missense and 2/6 variants were in-frame insertions. Of the 8 variants, 6 had a CADD score of $>20$. Patients 4 and 6 had in-frame insertions in $C B L$ and $I G F 1 R$ genes (CADD score 12.6 and not known, respectively). None of the patients had homozygous variants identified.

We classified the pathogenicity of the variants according to the American College of Medical Genetics and Genomics and the Association for Molecular Pathology (ACMG/AMP)'s standards and guidelines for the interpretation of sequence variants (30) (Table 3). Out of the 8 predicted deleterious variants, 7 were variants of 'uncertain significance' (30). Although the missense variants are very rare in populations (allele frequency
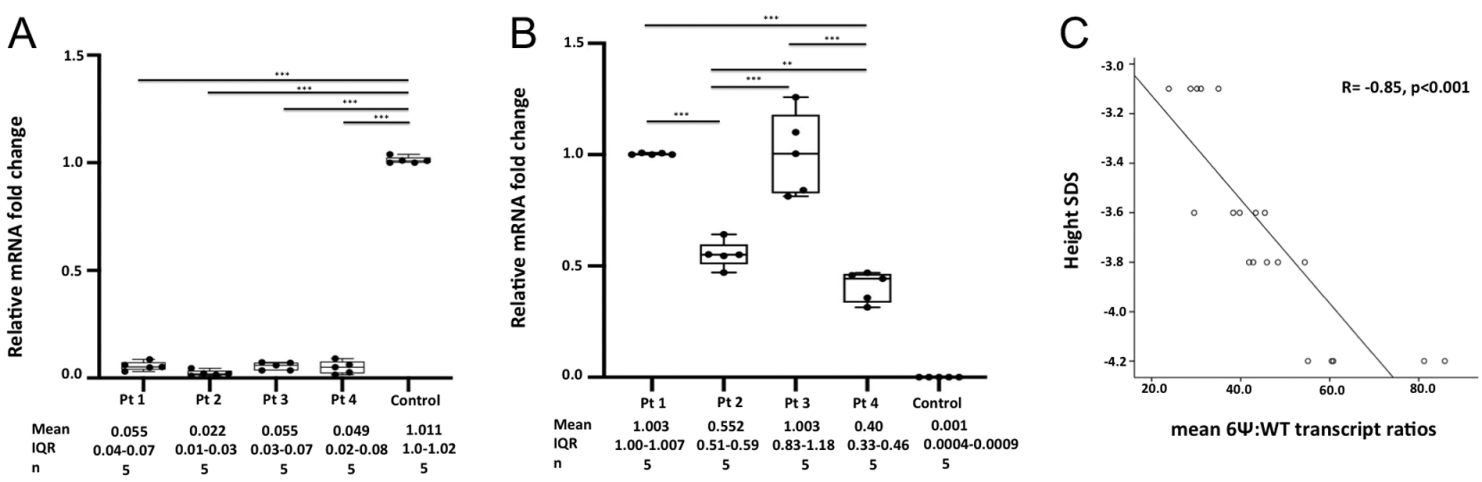

\section{Figure 2}

Quantitative RT-PCR (qRT-PCR). (A) Box and Whisker plot with jitter showing qRT-PCR of WT-GHR mRNA fold change relative to control. Box plots show the mean, upper and lower quartiles and range; IQR = interquartile range; $P$ values calculated by one way ANOVA with Bonferroni correction. $* * * P$ value $<0.001$. (B) Box and Whisker plot with jitter showing qRT-PCR of $6 \Psi-G H R$ mRNA fold change relative to Pt 1 . Box plots show the mean, upper and lower quartiles and range; IQR = interquartile range; $P$ values calculated by one-way ANOVA with Bonferroni correction. $* \star \star P$ value $<0.001$; $* \star P$ value $=0.017$. (C) Scatter plot showing the correlation between the height SDS at presentation and the mean $6 \Psi: W T$ transcript ratios in the four $6 \Psi$ patients. Pt, patient; $6 \Psi$, pseudoexon; WT, wild type; R, Pearson correlation coefficient.

https://ec.bioscientifica.com

https://doi.org/10.1530/EC-20-0026 (c) 2020 The authors Published by Bioscientifica Ltd

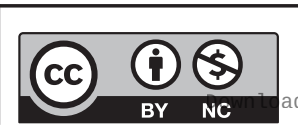

This work is licensed under a Creative Commons Attribution-NonCommercial 4.0 International License. ded from Bioscientifica.com at 04/26/2023 10:24:57AM 

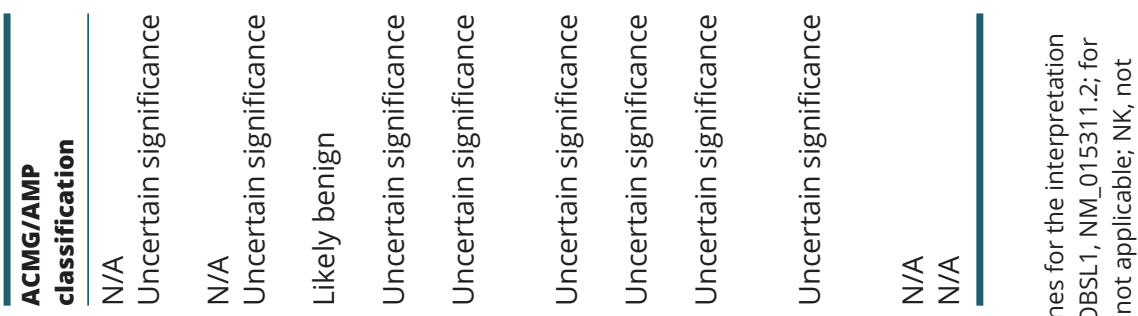

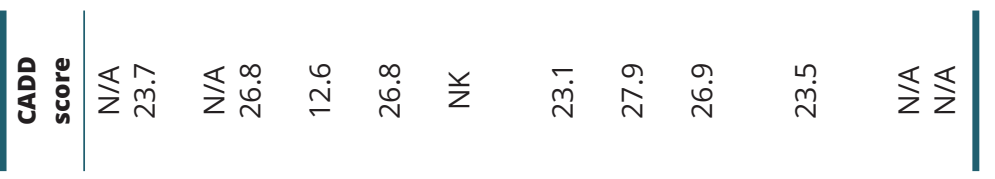

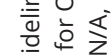

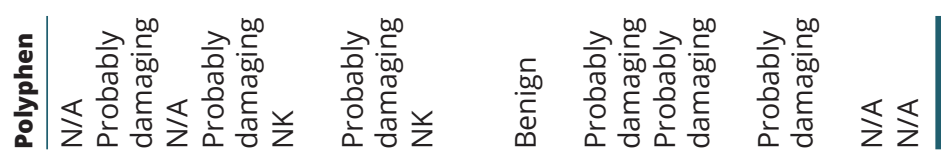

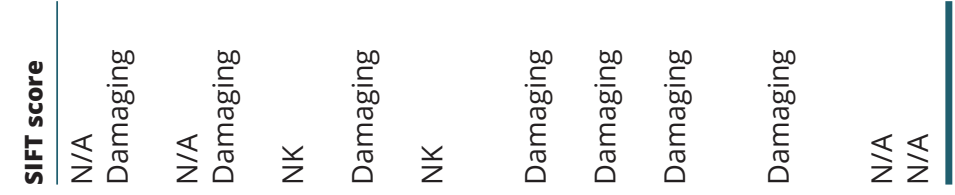

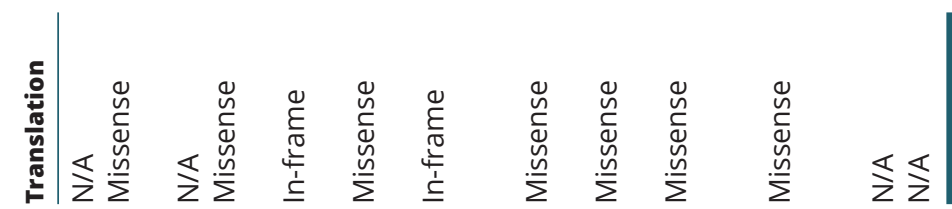

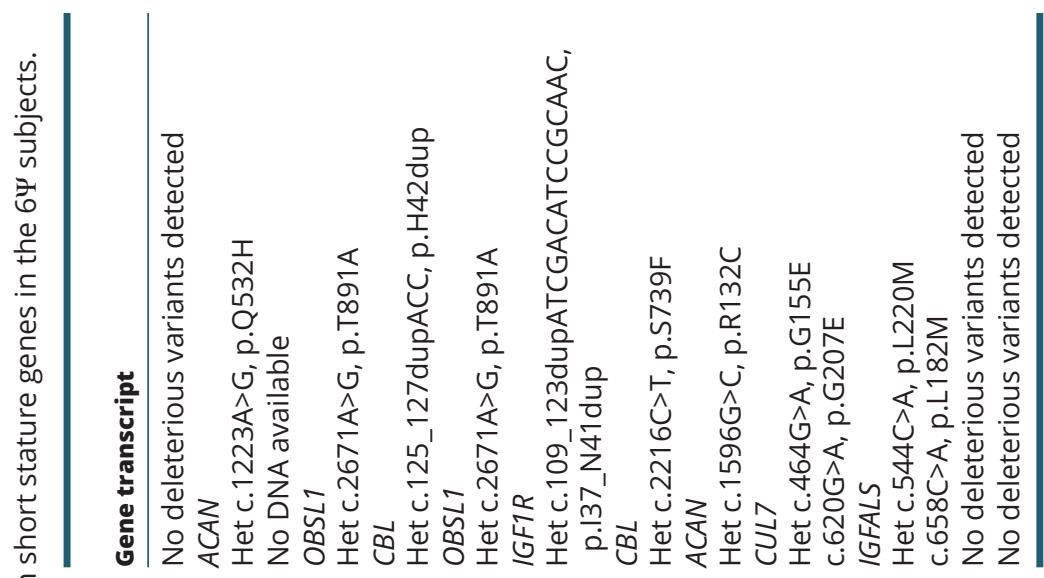

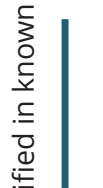

幽|

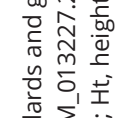

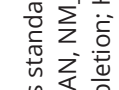

命造 웡

응 훈

帝 
$<0.001$ in the gnomAD database (31)) and in silico variant prediction tools support a deleterious effect on the gene, they fall into the category of 'uncertain significance' as they do not meet the criteria for being either pathogenic or benign (30). Furthermore, although the IGF1R heterozygous c.109_123dupATCGACATCCGCAAC, p.I37_N41dup in-frame insertion variant fulfils two moderate criteria for pathogenicity (30), that is, protein length changes as a result of in-frame deletion in a non-repeat region and is absent from controls as well as large databases (allele frequency 0.002 in the gnomAD database (31)), it does not strictly meet the ACMG/AMP criteria for pathogenicity and hence is classified as 'uncertain significance' (30). The CBL heterozygous c.125_127dupACC, p.H42dup variant is 'likely benign' (30), as it is an in-frame insertion in a repetitive region without known function and there is 1 homozygote in the gnomAD database (31).

Patients 2 and 8 with heterozygous ACAN variants did not have advanced bone maturation, early onset osteo-arthritis or intervertebral disc disease. Patient 6 (heterozygous in-frame IGF1R insertion) had normal birth weight, normal IGF-1 SDS, no developmental delay and consequently also did not fulfil the published criteria for the identification of patients with suspected IGF1R mutations (total score $<3$ ) (32). Patients 4 and 7 with CBL variants had no cardiac defects or developmental delay. Therefore, although these defects could potentially contribute to the short stature, no phenotypic features associated with these heterozygous genetic defects were detected.

In the four patients who underwent transcript heterogeneity analysis, three underwent genetic sequencing of short stature genes. Patient 2 had a heterozygous missense $A C A N$ variant. Patient 4 had a heterozygous missense OBSL1 variant and a heterozygous in-frame $C B L$ variant. Patient 1 had no predicted deleterious variants.

Reviewing all patients assessed on the gene panel (Table $3 ; n=11$ ), there was no correlation between the number of predicted deleterious genetic variants $(0,1$ or 2) and the degree of short stature (height SDS) in the individual $6 \Psi$ patients, that is, patient 4 had two variants and was not significantly shorter than those with one $(n=7)$ or no variant(s) $(n=3)$ (Table 3$)$. Additionally, the mean ( \pm S.D.) height SDS of patients with heterozygous or compound heterozygous variants in autosomal dominant inherited genes (ACAN, CBL and IGF1R) $(-3.78 \pm 0.67)$ was not significantly different from that of patients with heterozygous or compound heterozygous variants in autosomal recessive inherited genes (OBSL, CUL7, IGFALS) or patients with no deleterious variants $(-4.1 \pm 0.56)$, $P=0.39$.

\section{Discussion}

GH insensitivity (GHI) is a rare disorder caused by mutations in multiple GH-IGF1 axis genes. Homozygous GHR mutations are the commonest cause of 'classical' GHI and are associated with a wide range of clinical and biochemical phenotypes (33). More recently, it has been noted that several other short stature disorders such as $3 \mathrm{M}$, Noonan Syndrome (NS) and Silver-Russell Syndrome (SRS) overlap with GHI $(2,34,35,36,37)$.

Milder or 'non-classical' GHI cases are being increasingly recognised owing to advent of next generation sequencing techniques and an increased awareness of this group of disorders. Other molecular defects of the GH-IGF1 axis that cause 'non-classical' or milder GHI phenotypes include dominant negative GHR $(38,39,40,41)$ and STAT5B (42) gene mutations, heterozygous IGF1 $(43,44,45)$, IGF2 $(46,47)$ and IGFALS $(48,49)$ mutations, homozygous PAPPA2 (6) mutations

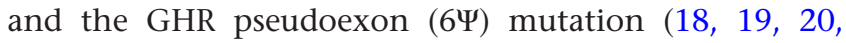
21). Non-classical GHI is an important clinical entity and the prevalence may be higher than classical GHI (2). Approximately 70 different GHR gene mutations have been reported in more than 300 patients $(1,2)$. A recent UK study (37) reporting the genetic diagnoses obtained from candidate gene and whole exome sequencing (WES) in a selected group of 107 patients with GHI showed that the GHR $6 \Psi$ mutation contributed to $25 \%(8 / 32)$ of GHR mutations and $16 \%(8 / 51)$ of all genetic diagnoses.

The GHR $6 \Psi$ mutation is notable, as striking phenotypic variability is observed between different patients harbouring the same homozygous point mutation, even among members of the same kindred (21). We hypothesise that several factors, alone or in combination, could contribute to the phenotypic variability observed between individual patients and include: (1.) differences in the levels of mutant vs WT GHR transcripts, (2.) concurrent genetic variants contributing to the degree of growth failure, (3.) environmental factors and (4.) genetic variability in the cellular processes that regulate the mutant and WT-GHR proteins. These are discussed in detail subsequently.

David et al. (19) suggested that the spectrum of clinical phenotypes observed in the GHR $6 \Psi$ patients may be due to competitive use of both WT and $6 \Psi$ mutant splice sites resulting in different ratios of the two transcripts. The current study tested the hypothesis that transcript heterogeneity could account for the phenotypic differences, particularly the severity of growth failure in the $6 \Psi$ subjects.

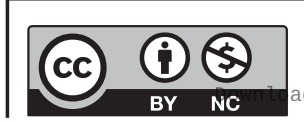

This work is licensed under a Creative Commons Attribution-NonCommercial 4.0 International License. ded from Bioscientifica.com at 04/26/2023 10:24:57AM 
We found variable levels of mutant $6 \Psi$-GHR mRNA expression among all patients except patients 1 and 3, who had similar height deficits of -3.6 and -3.8 , respectively. Our work implies that the splicing of the GHR pseudoexon is highly inconsistent, as variable quantities of mutant transcripts are produced in different individuals with the same mutation. Furthermore, consistent with our previous work (18), we confirmed the existence of WT-GHR transcript in the $6 \Psi$ subjects alongside the mutated $6 \Psi$ GHR transcript. This demonstrates that normal as well as abnormal splicing events co-exist in these subjects. Our results also confirm that a higher WT to mutant transcript ratio correlates negatively with the height SDS of the patients, that is, greater mutant pseudoexon inclusion may lead to a more severe phenotype.

Interestingly, consistent with previously published work (18), no GHR $6 \Psi$ transcript was detected in the control subject. This would indicate that under normal circumstances, the GHR pseudoexon splice site is not recognised by the splicing machinery, thereby preventing its inclusion in the mature mRNA. This corroborates the work by Akker et al. (8) who showed that the heterogenous nuclear ribonucleoprotein E1 (hnRNP E1) and small nuclear ribonucleoprotein U1 (snRNP U1) bind to the relatively weak 'wild-type' 5 ' GHR pseudoexon splice site in the pre-spliceosomal complex and silence it. The $A>G$ base change at the $5^{\prime}$ splice site in $6 \Psi$ patients does not create a new splice site but increases the bp match of the pre-mRNA with the snRNP U1. Therefore, the spliceosome recognises the GHR pseudoexon sequence and it is included in the mature mRNA of patients carrying the mutation (19).

Genotype-phenotype correlations secondary to variable splicing have been reported in three previous studies. Zhu (23) and Lemahieu et al. (24) investigated the association of different splice mutations of the WASP (Wiskott-Aldrich syndrome protein) gene with the clinical phenotypes of patients with WAS and X-linked thrombocytopaenia. Another study by Gurvich et al. (25) investigated the correlation between the clinical phenotypes of two patients and the splicing efficiency of two different intronic pseudoexon mutations in the $D M D$ (Duchenne muscular dystrophy) gene. All three studies demonstrated that relative amounts of mutant to normal transcripts positively correlated with the severity of the phenotypes of affected individuals. However, these studies examined different splice site mutations of the individual genes. Our work is the first to report the phenotypic impact of transcript heterogeneity in patients with an identical homozygous splice mutation.
The potential underlying mechanism(s) leading to a spectrum of phenotypes in subjects with the same genetic mutation are unclear. Gurvich et al. (25) proposed that the difference in splicing efficiency between the two different $D M D$ gene mutations could be attributed to the strength of the donor splice sites created by the mutation and/or the strength of the cryptic acceptor splice sites in the WT sequence which are further activated by the point mutations. This explanation would not be applicable to our patients, as the $6 \Psi$ intronic point mutation leads to activation of the same $5^{\prime}$ donor splice site in all the subjects.

David et al. (19) also suggested that the genetic background of individual patients and/or environmental factors may play a role in determining the differential use of WT vs mutant splice sites and thus generation of variable quantities of normal vs mutated transcript. Variations in the core spliceosome machinery (comprising hnRNP and snRNP) and variations in genes encoding RNA processing/RNA-binding factors can influence alternative splicing $(50,51,52)$. It is possible that differences in these factors between $6 \Psi$ patients regulate the differential use of the mutated and WT splice sites and thus determine the amount of mutant vs WT transcript generated.

It is feasible that the GHI phenotype, particularly the severity of the growth failure observed in the $6 \Psi$ patients, is influenced by genetic variants in different genetic loci. We sought concurrent defects in genes known to cause short stature, GH insensitivity and overlapping phenotypes, for example, Noonan, Silver-Russell and 3M Syndrome in $116 \Psi$ patients.

Analysis of 40 genes (including intronic and promoter regions) revealed that a significant proportion (73\%) of $6 \Psi$ subjects had predicted deleterious heterozygous or compound heterozygous genetic variants. Of these, three variants in ACAN, IGF1R and CBL genes are recognised to have an autosomal dominant pattern of inheritance leading to short stature $(53,54,55)$. It is possible that these variants contributed to the growth failure in patients 2, 4, 6, 7 and 8 . However, none of these patients had additional phenotypic features that would be consistent with the identified additional genetic variant. Furthermore, there was no difference in height SDS between the patients with heterozygous/compound heterozygous variants in genes with an autosomal dominant pattern of inheritance compared to patients with heterozygous/compound heterozygous variants in genes with an autosomal recessive inheritance or patients with no deleterious variants. This implies that the ACAN, 
IGF1R and CBL gene variants identified did not impact significantly on the patient's phenotypes. Unfortunately, we were unable to perform segregation studies as parental DNA was not available for any of the subjects. However, consistent with our findings, a previous study of two $6 \Psi$ patients also demonstrated that other genetic variants did not contribute to the severity of the phenotypes (20).

Interestingly, given that the majority of patients have consanguineous family structures, no homozygous variants were detected. We were also unable to identify a correlation between the number of predicted deleterious variants and the severity of short stature in the individual GHR $6 \Psi$ patients studied. This indicates that concurrent defects in this subset of known short stature, GHI and overlapping disorders genes do not appear to contribute to the growth phenotype in these patients. We cannot, however, rule out an impact of other known short stature genes or currently undiscovered short stature genes. It is also possible that multiple genes with smaller effect size could account for some or all of the clinical variation.

Genotyping a region spanning $17.10 \mathrm{Mb}$ around the GHR gene on chromosome 5 and analysis of the complex single polymorphic region in intron 9 of the GHR in five GHR $6 \Psi$ families showed the same genotype for all affected members, suggesting the presence of a common ancestor (19). Furthermore, 19/22 of the known GHR pseudoexon patients are of Pakistani ethnicity $(18,19,20,21)$. This implies that the GHR $6 \Psi$ patient cohort share a common genetic background. This is comparable to the p.E180 splice GHR mutation found predominantly in individuals from Ecuador, Brazil and Chile, where a shared genetic background flanking the splice mutation was identified $(56,57)$. First degree relatives who are heterozygous carriers of the p.E180 mutation are modestly shorter than non-carrier relatives (58). This is in contrast to our cohort, where heterozygous carrier parents of $6 \Psi$ patients had normal stature (19).

It is recognised that a multitude of environmental factors such as nutrition, socio-economic status and adverse environmental conditions affect childhood growth $(59,60)$. It is possible that any of these factors contribute to the phenotypic variability observed in our patient cohort. However, as there are marked differences between affected individuals within the same kindred, environmental factors are unlikely to be very significant.

It is feasible that differences in processing, trafficking and degradation of the mutant and WT GH receptor proteins account for the clinical differences (19). Maamra et al. (22) confirmed that the mutant GHR $6 \Psi$ protein compromised normal cell surface trafficking but signalling was unimpaired. Therefore, variability in genes regulating these cellular processes might conceivably have a greater influence on the mutant $6 \Psi$ GHR protein than the WT GHR. Further work exploring this hypothesis is required.

It is important to acknowledge that our study has several limitations. First, GHR transcript ratios were studied in only four $6 \Psi$ patients. Furthermore, one of the four patients was not assessed on the gene panel. Our work would not identify variants in other known short stature genes not included in the panel or defects in currently undiscovered short stature genes. Additionally, the phenotypic spectrum of individual genetic defects is expected to broaden as more patients are reported. Finally, we did not explore the mechanisms underlying the observed variable splicing or genetic variability which might affect GHR protein processing, trafficking and degradation. Further work is required to address these.

In conclusion, our work shows that there is a variable ratio of mutated and WT-GHR mRNA transcripts in GHR $6 \Psi$ patients. The mutated GHR $6 \Psi$ transcript is not normally spliced in unaffected subjects. Patients with more severe phenotypes, that is, lower height SDS, have a GHR transcript ratio in favour of the mutant GHR. The reason for the variable splicing in different patients with the same mutation is fascinating. The genetic background of individuals may influence this. However, our preliminary work does not suggest that variants in candidate SS genes contribute significantly to the variability of growth failure. This is the first indication that variable splicing and transcript heterogeneity can lead to a range of short stature phenotypes in subjects harbouring the same genetic mutation.

\section{Declaration of interest}

The authors declare that there is no conflict of interest that could be perceived as prejudicing the impartiality of the research reported.

\section{Funding}

The genetic sequencing service was supported by a large project research grant from Barts charity (H L S). S C was supported by Barts Charity Clinical Research Training Fellowship.

\section{Author contribution statement}

S C, S J R, T M and H L S contributed to patient recruitment, data collection and analysis. S C, E C and L A M performed the genetic analysis. S C performed the molecular work and statistical analyses with support from $A \vee M$ and J W. S C wrote the manuscript with input from L A M, M O S and HLS.
This work is licensed under a Creative Commons Attribution-NonCommercial 4.0 International License. ded from Bioscientifica.com at 04/26/2023 10:24:57AM via free access 


\section{References}

1 David A, Hwa V, Metherell LA, Netchine I, Camacho-Hubner C, Clark AJ, Rosenfeld RG \& Savage MO. Evidence for a continuum of genetic, phenotypic, and biochemical abnormalities in children with growth hormone insensitivity. Endocrine Reviews 201132 472-497. (https://doi.org/10.1210/er.2010-0023)

2 Storr HL, Chatterjee S, Metherell LA, Foley C, Rosenfeld RG, Backeljauw PF, Dauber A, Savage MO \& Hwa V. Nonclassical GH insensitivity: characterization of mild abnormalities of GH action. Endocrine Reviews 201940 476-505. (https://doi.org/10.1210/er.201800146)

3 Amselem S, Duquesnoy P, Attree O, Novelli G, Bousnina S, PostelVinay MC \& Goossens M. Laron dwarfism and mutations of the growth hormone-receptor gene. New England Journal of Medicine 1989 321 989-995. (https://doi.org/10.1056/NEJM198910123211501)

4 Kofoed EM, Hwa V, Little B, Woods KA, Buckway CK, Tsubaki J, Pratt KL, Bezrodnik L, Jasper H, Tepper A, et al. Growth hormone insensitivity associated with a STAT5b mutation. New England Journal of Medicine 2003349 1139-1147. (https://doi.org/10.1056/ NEJMoa022926)

5 Domené HM, Bengolea SV, Martinez AS, Ropelato MG, Pennisi P, Scaglia P, Heinrich JJ \& Jasper HG. Deficiency of the circulating insulin-like growth factor system associated with inactivation of the acid-labile subunit gene. New England Journal of Medicine 2004350 570-577. (https://doi.org/10.1056/NEJMoa013100)

6 Dauber A, Munoz-Calvo MT, Barrios V, Domene HM, Kloverpris S, Serra-Juhe C, Desikan V, Pozo J, Muzumdar R, Martos-Moreno GÁ, et al. Mutations in pregnancy-associated plasma protein $\mathrm{A} 2$ cause short stature due to low IGF-I availability. EMBO Molecular Medicine 20168 363-374. (https://doi.org/10.15252/emmm.201506106)

7 Woods KA, Camacho-Hubner C, Savage MO \& Clark AJ. Intrauterine growth retardation and postnatal growth failure associated with deletion of the insulin-like growth factor I gene. New England Journal of Medicine 1996335 1363-1367. (https://doi.org/10.1056/ NEJM199610313351805)

8 Akker SA, Misra S, Aslam S, Morgan EL, Smith PJ, Khoo B \& Chew SL. Pre-spliceosomal binding of U1 small nuclear ribonucleoprotein (RNP) and heterogenous nuclear RNP E1 is associated with suppression of a growth hormone receptor pseudoexon. Molecular Endocrinology 2007 21 2529-2540. (https://doi.org/10.1210/me.2007-0038)

9 Dunham I, Shimizu N, Roe BA, Chissoe S, Hunt AR, Collins JE, Bruskiewich R, Beare DM, Clamp M, Smink LJ, et al. The DNA sequence of human chromosome 22. Nature 1999402 489-495. (https://doi.org/10.1038/990031)

10 Sun $\mathrm{H} \&$ Chasin LA. Multiple splicing defects in an intronic false exon. Molecular and Cellular Biology 200020 6414-6425. (https://doi. org/10.1128/mcb.20.17.6414-6425.2000)

11 Dhir A \& Buratti E. Alternative splicing: role of pseudoexons in human disease and potential therapeutic strategies. FEBS Journal 2010 277 841-855. (https://doi.org/10.1111/j.1742-4658.2009.07520.x)

12 Fairbrother WG \& Chasin LA. Human genomic sequences that inhibit splicing. Molecular and Cellular Biology 200020 6816-6825. (https://doi.org/10.1128/mcb.20.18.6816-6825.2000)

13 Zhang XH \& Chasin LA. Computational definition of sequence motifs governing constitutive exon splicing. Genes and Development 200418 1241-1250. (https://doi.org/10.1101/gad.1195304)

14 Pagani F, Buratti E, Stuani C, Bendix R, Dork T \& Baralle FE. A new type of mutation causes a splicing defect in ATM. Nature Genetics 200230 426-429. (https://doi.org/10.1038/ng858)

15 Zhang XH, Leslie CS \& Chasin LA. Dichotomous splicing signals in exon flanks. Genome Research 200515 768-779. (https://doi. org/10.1101/gr.3217705)

16 Nakai K \& Sakamoto H. Construction of a novel database containing aberrant splicing mutations of mammalian genes. Gene 1994141 171-177. (https://doi.org/10.1016/0378-1119(94)90567-3)
17 Krawczak M, Reiss J \& Cooper DN. The mutational spectrum of single base-pair substitutions in mRNA splice junctions of human genes: causes and consequences. Human Genetics 199290 41-54. (https://doi.org/10.1007/bf00210743)

18 Metherell LA, Akker SA, Munroe PB, Rose SJ, Caulfield M, Savage MO, Chew SL \& Clark AJ. Pseudoexon activation as a novel mechanism for disease resulting in atypical growth-hormone insensitivity. American Journal of Human Genetics 200169 641-646. (https://doi. org/10.1086/323266)

19 David A, Camacho-Hubner C, Bhangoo A, Rose SJ, Miraki-Moud F, Akker SA, Butler GE, Ten S, Clayton PE, Clark AJ, et al. An intronic growth hormone receptor mutation causing activation of a pseudoexon is associated with a broad spectrum of growth hormone insensitivity phenotypes. Journal of Clinical Endocrinology and Metabolism 200792 655-659. (https://doi.org/10.1210/jc.2006-1527)

20 Walenkamp MJE, Klammt J, Feigerlova E, Losekoot M, van Duyvenvoorde HA, Hwa V, Pfäffle R \& Wit JM. Genetic analysis of GHR should contain sequencing of all coding exons and specific intron sequences, and screening for exon deletions. Hormone Research in Paediatrics 201380 406-412. (https://doi.org/10.1159/000355928)

21 Chatterjee S, Shapiro L, Rose SJ, Mushtaq T, Clayton PE, Ten SB, Bhangoo A, Kumbattae U, Dias R, Savage MO, et al. Phenotypic spectrum and responses to recombinant human igf1 (rhigf1) therapy in patients with homozygous intronic pseudoexon growth hormone receptor mutation. European Journal of Endocrinology 2018178 481-489. (https://doi.org/10.1530/EJE-18-0042)

22 Maamra M, Milward A, Esfahani HZ, Abbott LP, Metherell LA, Savage MO, Clark AJ \& Ross RJ. A 36 residues insertion in the dimerization domain of the growth hormone receptor results in defective trafficking rather than impaired signaling. Journal of Endocrinology 2006188 251-261. (https://doi.org/10.1677/ joe.1.06252)

23 Zhu Q, Watanabe C, Liu T, Hollenbaugh D, Blaese RM, Kanner SB, Aruffo A \& Ochs HD. Wiskott-Aldrich syndrome/X-linked thrombocytopenia: WASP gene mutations, protein expression, and phenotype. Blood 199790 2680-2689.

24 Lemahieu V, Gastier JM \& Francke U. Novel mutations in the Wiskott-Aldrich syndrome protein gene and their effects on transcriptional, translational, and clinical phenotypes. Human Mutation 1999 14 54-66. (https://doi.org/10.1002/(SICI)10981004(1999)14:1<54::AID-HUMU7>3.0.CO;2-E)

25 Gurvich OL, Tuohy TM, Howard MT, Finkel RS, Medne L, Anderson CB, Weiss RB, Wilton SD \& Flanigan KM. DMD pseudoexon mutations: splicing efficiency, phenotype, and potential therapy. Annals of Neurology 200863 81-89. (https://doi.org/10.1002/ ana.21290)

26 Freeman JV, Cole TJ, Chinn S, Jones PR, White EM \& Preece MA. Cross sectional stature and weight reference curves for the UK, 1990. Archives of Disease in Childhood 199573 17-24. (https://doi. org/10.1136/adc.73.1.17)

27 WHO Multicentre Growth Reference Study Group. WHO child growth standards based on length/height, weight and age. Acta Paediatrica: Supplement $2006 \mathbf{4 5 0}$ 76-85.

28 Poliandri A, Miller D, Howard S, Nobles M, Ruiz-Babot G, Harmer S, Tinker A, McKay T, Guasti L \& Dunkel L. Generation of kisspeptinresponsive GnRH neurons from human pluripotent stem cells. Molecular and Cellular Endocrinology 2017447 12-22. (https://doi. org/10.1016/j.mce.2017.02.030)

29 Maharaj A, Buonocore F, Meimaridou E, Ruiz-Babot G, Guasti L, Peng HM, Capper CP, Burgos-Tirado N, Prasad R, Hughes CR, et al. Predicted benign and synonymous variants in CYP11A1 cause primary adrenal insufficiency through missplicing. Journal of the Endocrine Society 20193 201-221. (https://doi.org/10.1210/js.201800130)

30 Richards S, Aziz N, Bale S, Bick D, Das S, Gastier-Foster J, Grody WW, Hegde M, Lyon E, Spector E, et al. Standards and guidelines

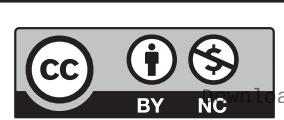

This work is licensed under a Creative Commons Attribution-NonCommercial 4.0 International License. aded from Bioscientifica.com at 04/26/2023 10:24:57 AM 
for the interpretation of sequence variants: a joint consensus recommendation of the American College of Medical Genetics and Genomics and the Association for Molecular Pathology. Genetics in Medicine 201517 405-424. (https://doi.org/10.1038/gim.2015.30)

31 Karczewski KJ, Francioli LC, Tiao G, Cummings BB, Alföldi J, Wang Q, Collins RL, Laricchia KM, Ganna A, Birnbaum DP, et al. Variation across 141,456 human exomes and genomes reveals the spectrum of loss-of-function intolerance across human proteincoding genes. bioRxiv 2019 531210. (https://doi.org/10.1101/531210)

32 Walenkamp MJE, Robers JML, Wit JM, Zandwijken GRJ, van Duyvenvoorde HA, Oostdijk W, Hokken-Koelega ACS, Kant SG \& Losekoot M. Phenotypic features and response to GH treatment of patients with a molecular defect of the IGF-1 receptor. Journal of Clinical Endocrinology and Metabolism 2019104 3157-3171. (https:// doi.org/10.1210/jc.2018-02065)

33 Lin S, Li C, Li C \& Zhang X. Growth hormone receptor mutations related to individual dwarfism. International Journal of Molecular Sciences 201819 1433. (https://doi.org/10.3390/ijms19051433)

34 Akawi NA, Ali BR, Hamamy H, Al-Hadidy A \& Al-Gazali L. Is autosomal recessive silver-Russel syndrome a separate entity or is it part of the 3-M syndrome spectrum? American Journal of Medical Genetics. Part A 2011 155A 1236-1245. (https://doi.org/10.1002/ ajmg.a.34009)

35 Binder G, Neuer K, Ranke MB \& Wittekindt NE. PTPN11 mutations are associated with mild growth hormone resistance in individuals with Noonan syndrome. Journal of Clinical Endocrinology and Metabolism 200590 5377-5381. (https://doi.org/10.1210/jc.20050995)

36 Storr HL, Dunkel L, Kowalczyk J, Savage MO \& Metherell LA. Genetic characterisation of a cohort of children clinically labelled as GH or IGF1 insensitive: diagnostic value of serum IGF1 and height at presentation. European Journal of Endocrinology 2015172 151-161. (https://doi.org/10.1530/EJE-14-0541)

37 Shapiro L, Chatterjee S, Ramadan DG, Davies KM, Savage MO, Metherell LA \& Storr HL. Whole-exome sequencing gives additional benefits compared to candidate gene sequencing in the molecular diagnosis of children with growth hormone or IGF-1 insensitivity. European Journal of Endocrinology 2017177 485-501. (https://doi. org/10.1530/EJE-17-0453)

38 Vairamani K, Merjaneh L, Casano-Sancho P, Sanli ME, David A, Metherell LA, Savage MO, Del Pozo JS, Backeljauw PF, Rosenfeld RG, et al. Novel dominant-negative GH receptor mutations expands the spectrum of GHI and IGF-I deficiency. Journal of the Endocrine Society 20171 345-358. (https://doi.org/10.1210/js.2016-1119)

39 Ayling RM, Ross R, Towner P, Von Laue S, Finidori J, Moutoussamy S, Buchanan CR, Clayton PE \& Norman MR. A dominant-negative mutation of the growth hormone receptor causes familial short stature. Nature Genetics 199716 13-14. (https://doi.org/10.1038/ ng0597-13)

40 Iida K, Takahashi Y, Kaji H, Nose O, Okimura Y, Abe H \& Chihara K. Growth hormone $(\mathrm{GH})$ insensitivity syndrome with high serum GH-binding protein levels caused by a heterozygous splice site mutation of the GH receptor gene producing a lack of intracellular domain. Journal of Clinical Endocrinology and Metabolism $1998 \mathbf{8 3}$ 531-537. (https://doi.org/10.1210/jcem.83.2.4601)

41 Aisenberg J, Auyeung V, Pedro HF, Sugalski R, Chartoff A, Rothenberg R, Derr MA, Hwa V \& Rosenfeld RG. Atypical GH insensitivity syndrome and severe insulin-like growth factor-I deficiency resulting from compound heterozygous mutations of the GH receptor, including a novel frameshift mutation affecting the intracellular domain. Hormone Research in Paediatrics 201074 406-411. (https://doi.org/10.1159/000314968)

42 Klammt J, Neumann D, Gevers EF, Andrew SF, Schwartz ID, Rockstroh D, Colombo R, Sanchez MA, Vokurkova D, Kowalczyk J, et al. Dominant-negative STAT5B mutations cause growth hormone insensitivity with short stature and mild immune dysregulation.
Nature Communications 20189 2105. (https://doi.org/10.1038/ s41467-018-04521-0)

43 van Duyvenvoorde HA, van Setten PA, Walenkamp MJ, van Doorn J, Koenig J, Gauguin L, Oostdijk W, Ruivenkamp CA, Losekoot M, Wade JD, et al. Short stature associated with a novel heterozygous mutation in the insulin-like growth factor 1 gene. Journal of Clinical Endocrinology and Metabolism 201095 E363-E367. (https://doi. org/10.1210/jc.2010-0511)

44 Batey L, Moon JE, Yu Y, Wu B, Hirschhorn JN, Shen Y \& Dauber A. A novel deletion of IGF1 in a patient with idiopathic short stature provides insight into IGF1 haploinsufficiency. Journal of Clinical Endocrinology and Metabolism 201499 E153-E159. (https://doi. org/10.1210/jc.2013-3106)

45 Fuqua JS, Derr M, Rosenfeld RG \& Hwa V. Identification of a novel heterozygous IGF1 splicing mutation in a large kindred with familial short stature. Hormone Research in Paediatrics 201278 59-66. (https:// doi.org/10.1159/000337249)

46 Begemann M, Zirn B, Santen G, Wirthgen E, Soellner L, Büttel HM, Schweizer R, van Workum W, Binder G \& Eggermann T. Paternally inherited IGF2 mutation and growth restriction. New England Journal of Medicine 2015373 349-356. (https://doi.org/10.1056/ NEJMoa1415227)

47 Yamoto K, Saitsu H, Nakagawa N, Nakajima H, Hasegawa T, Fujisawa Y, Kagami M, Fukami M \& Ogata T. De novo IGF2 mutation on the paternal allele in a patient with Silver-Russell syndrome and ectrodactyly. Human Mutation 201738 953-958. (https://doi. org/10.1002/humu.23253)

48 Grandone A, Miraglia del Giudice E, Cirillo G, Abbondanza C, Cioffi M, Romano T, Micillo F, Marzuillo P \& Perrone L. Clinical features of a new acid-labile subunit (IGFALS) heterozygous mutation: anthropometric and biochemical characterization and response to growth hormone administration. Hormone Research in Paediatrics 201481 67-72. (https://doi.org/10.1159/000355017)

49 Fofanova-Gambetti OV, Hwa V, Wit JM, Domene HM, Argente J, Bang P, Högler W, Kirsch S, Pihoker C, Chiu HK, et al. Impact of heterozygosity for acid-labile subunit (IGFALS) gene mutations on stature: results from the international acid-labile subunit consortium. Journal of Clinical Endocrinology and Metabolism 201095 4184-4191. (https://doi.org/10.1210/jc.2010-0489)

50 Chen M \& Manley JL. Mechanisms of alternative splicing regulation: insights from molecular and genomics approaches. Nature Reviews: Molecular Cell Biology 200910 741-754. (https://doi.org/10.1038/ nrm2777)

51 Nilsen TW \& Graveley BR. Expansion of the eukaryotic proteome by alternative splicing. Nature 2010463 457-463. (https://doi. org/10.1038/nature08909)

52 Saltzman AL, Pan Q \& Blencowe BJ. Regulation of alternative splicing by the core spliceosomal machinery. Genes and Development 201125 373-384. (https://doi.org/10.1101/gad.2004811)

53 Stattin EL, Wiklund F, Lindblom K, Onnerfjord P, Jonsson BA, Tegner Y, Sasaki T, Struglics A, Lohmander S, Dahl N, et al. A missense mutation in the aggrecan C-type lectin domain disrupts extracellular matrix interactions and causes dominant familial osteochondritis dissecans. American Journal of Human Genetics 2010 86 126-137. (https://doi.org/10.1016/j.ajhg.2009.12.018)

54 Abuzzahab MJ, Schneider A, Goddard A, Grigorescu F, Lautier C, Keller E, Kiess W, Klammt J, Kratzsch J, Osgood D, et al. IGF-I receptor mutations resulting in intrauterine and postnatal growth retardation. New England Journal of Medicine 2003349 2211-2222. (https://doi.org/10.1056/NEJMoa010107)

55 Martinelli S, De Luca A, Stellacci E, Rossi C, Checquolo S, Lepri F, Caputo V, Silvano M, Buscherini F, Consoli F, et al. Heterozygous germline mutations in the CBL tumor-suppressor gene cause a Noonan syndrome-like phenotype. American Journal of Human Genetics 201087 250-257. (https://doi.org/10.1016/j. ajhg.2010.06.015)

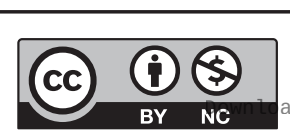

This work is licensed under a Creative Commons Attribution-NonCommercial 4.0 International License. ded from Bioscientifica com at 04/26/2023 10:24:57 AM 
56 Jorge AA, Menezes Filho HC, Lins TS, Guedes DR, Damiani D, Setian N, Arnhold IJ \& Mendonça BB. Founder effect of E180splice mutation in growth hormone receptor gene (GHR) identified in Brazilian patients with GH insensitivity. Arquivos Brasileiros de Endocrinologia e Metabologia 200549 384-389. (https://doi. org/10.1590/s0004-27302005000300009)

57 Espinosa C, Sjoberg M, Salazar T, Rodriguez A, Cassorla FG, Mericq MV \& Carvallo P. E180splice mutation in the growth hormone receptor gene in a Chilean family with growth hormone insensitivity: a probable common Mediterranean ancestor. Journal of Pediatric Endocrinology and Metabolism 200821 1119-1127. (https:// doi.org/10.1515/jpem.2008.21.12.1119)

58 Guevara-Aguirre J, Rosenbloom AL, Guevara-Aguirre M, Yariz K, Saavedra J, Baumbach L \& Shuster J. Effects of heterozygosity for the E180 splice mutation causing growth hormone receptor deficiency in Ecuador on IGF-I, IGFBP-3, and stature. Growth Hormone and IGF Research 200717 261-264. (https://doi.org/10.1016/j. ghir.2007.01.016)

59 Bozzoli C, Deaton A \& Quintana-Domeque C. Adult height and childhood disease. Demography 200946 647-669. (https://doi. org/10.1353/dem.0.0079)
60 Gat-Yablonski G \& De Luca F. Effect of nutrition on statural growth. Hormone Research in Paediatrics 201788 46-62. (https://doi. org/10.1159/000456547)

61 Dateki S, Nakatomi A, Watanabe S, Shimizu H, Inoue Y, Baba H, Yoshiura KI \& Moriuchi H. Identification of a novel heterozygous mutation of the aggrecan gene in a family with idiopathic short stature and multiple intervertebral disc herniation. Journal of Human Genetics 201762 717-721. (https://doi.org/10.1038/jhg.2017.33)

62 Nilsson O, Guo MH, Dunbar N, Popovic J, Flynn D, Jacobsen C, Lui JC, Hirschhorn JN, Baron J \& Dauber A. Short stature, accelerated bone maturation, and early growth cessation due to heterozygous aggrecan mutations. Journal of Clinical Endocrinology and Metabolism 201499 E1510-E1518. (https://doi.org/10.1210/jc.2014-1332)

63 Wang SR, Jacobsen CM, Carmichael H, Edmund AB, Robinson JW, Olney RC, Miller TC, Moon JE, Mericq V, Potter LR, et al. Heterozygous mutations in natriuretic peptide receptor-B (NPR2) gene as a cause of short stature. Human Mutation 201536 474-481. (https://doi.org/10.1002/humu.22773)

64 Binder G. Short stature due to SHOX deficiency: genotype, phenotype, and therapy. Hormone Research in Paediatrics 201175 81-89. (https://doi.org/10.1159/000324105)

Received in final form 23 January 2020

Accepted 12 February 2020

Accepted Manuscript published online 12 February 2020
This work is licensed under a Creative Commons Attribution-NonCommercial 4.0 International License. ded from Bioscientifica.com at 04/26/2023 10:24:57AM 